\title{
EL ROMANCERO EN LA PRIMERA PARTE DEL QUIJOTE
}

Así calificó el narrador del Ingenioso hidalgo don Quijote de la Mancha al entonces popularísimo romance del Marqués de Mantua: “...historia sabida de los niños, no ignorada de los mozos, celebrada y aun creída de los viejos, y, con todo esto, no más verdadera que los milagros de Mahoma" (I, 5, 103) ${ }^{1}$. Años después, Mateo Alemán y Rodrigo Caro nos informan que los pliegos sueltos de este mismo romance se utilizaban en las escuelas para enseñar a leer a los niños (y, de paso, adormecerlos, pues el poema consta de más de ¡400 versos dieciseisílabos! ${ }^{2}$. No sabemos si Cervantes fue uno de estos niños, en todo caso, lo que es evidente es que él, como Alemán y Caro, y como todo hombre de su tiempo, sabía muchos romances, y no dejó de aprovechar ese conocimiento en algunas de sus obras, por ejemplo, El Quijote. Hay romances en las dos partes de la novela, que, como es sabido, fueron publicadas con diez años de diferencia. Sin duda, tales años no fueron ociosos, ni para el autor, ni para la historia de don Quijote, pues entre el texto de 1605 y el de 1615 hay grandes diferencias. Una de ellas tiene que ver con el romancero.

${ }^{1}$ Para todos los casos sigo la edición que Luis Andrés MuriLlo preparó para Clásicos Castalia (Madrid, 1982). En adelante, indico en el texto la parte, el capítulo y las páginas. Ocasionalmente, remitiré a las notas de Francisco Rodríguez Marín, incluidas en la edición del Patronato del IV Centenario de Cervantes (Madrid, 1947-1949).

${ }^{2}$ En 1609, Mateo Alemán critica los errores de los viejos métodos de enseñanza, en los siguientes términos: "Començávamos niños, i salíamos casi barbados a la Gramática, pasándose lo mejor de la vida entre las coplas de Marqués de Mantua, i fecha la plana" (Ortografía castellana, ed. J. Rojas Garcidueñas, El Colegio de México, México, 1950, p. 24). En una composición festiva que se conserva en la Biblioteca Colombina de Sevilla, Rodrigo Caro exclama: ";Oh, noble Marqués de Mantua!, / qué de veces repetido / fue tu caso lastimero / que en la escuela deprendimos" (apud F. Rodríguez Marín, ed. cit., t. 1, p. 173, nota). 
Si revisamos el conjunto de la obra, encontraremos que en la Primera parte hay pocos romances, frente a lo que ocurre en la Segunda, donde el número y la variedad de ejemplos se incrementa notablemente. Semejante contraste puede llevarnos a pensar que es en la última parte donde nuestro género alcanza mayor peso, quizá así sea, pero los romances de la Primera parte también poseen su propio interés, entre otras cosas, porque gracias a ellos Cervantes exploró varias de las posibilidades que desarrollará al escribir la historia de la tercera salida de don Quijote. En esta ocasión, veremos qué es lo que el texto de 1605 nos aporta en materia romancística.

\section{ROMANCES PREFERIDOS}

En la obra aparecen siete romances, citados parcial o totalmente por don Quijote, el narrador u otros personajes ${ }^{3}$. En este pequeño grupo hay dos tipos de poemas, que, a su vez, corresponden a dos géneros completamente distintos:

a) Romances viejos, es decir, aquellos romances anónimos que se venían cantando desde la Edad Media, por toda clase de gente, a lo largo y ancho de la Península ibérica (e, incluso, más allá de las fronteras nacionales); los romances viejos del Quijote son cuatro: Mis arreos son las armas... o La constancia (I, 2, 84-85), Lanzarote y el orgulloso (I, 2, 85; 13, 170-171), el ya mencionado Marqués de Mantua (I, 5, 103-104; 10, 150-151; 19, 228; 31, 383) y En el val de las estacas... $(\mathrm{I}, 17,206)^{4}$. Quizá habría que considerar también los versos "de los que dicen las gentes / que van a sus aventuras" o "destos que dicen las gentes / que a sus aventuras van" (I, 9, 40; 49, 581 ), que, por su estilo, bien podrían pertenecer a un romance viejo hoy desconocido ${ }^{5}$.

${ }^{3}$ En el recuento que sigue no incluyo las meras alusiones a personajes o episodios romancísticos, donde no se citan o refunden versos concretos, por ejemplo, el desacato que hizo el Cid al Papa, mencionado por don Quijote en el episodio del cuerpo muerto (I, 19, 235-236). Por la misma razón, dejo para otro momento el análisis de los paralelos entre la figura de Cardenio loco y el protagonista de Por unos puertos arriba... (RAmón Menéndez Pidal, "Un aspecto en la elaboración del Quijote", De Cervantes y Lope de Vega, Espasa-Calpe, Buenos Aires, 1943, pp. 32-33).

${ }^{4}$ En el texto de 1615 reaparecen Lanzarote y el orgulloso (II, 23, 220; 31, 275) y el Marqués de Mantua (II, 23, 222; 32, 288).

${ }^{5}$ La otra posibilidad, ya apuntada por Rodríguez Marín (ed. cit., t. 1, pp. 275276, nota), es que los versos se deben a la pluma de Alvar Gómez de Ciudad 
b) Romances nuevos, o sea, los romances escritos por poetas cortesanos en las dos últimas décadas del siglo xvı y la primera del xvII; aunque estas nuevas composiciones conservan la métrica y uno que otro recuerdo de los antiguos romances, en definitiva, su estilo es el de la poesía culta coetánea. En nuestra obra hay tres ejemplos de este tipo. Uno de ellos es el que comienza “¿Dónde estás, señora mía...?” (I, 5, 103) y es, en realidad, un contrafactum del texto viejo del Marqués de Mantua; el romance nuevo se debe a Jerónimo Treviño y se imprimió en Alcalá, en 1598 (también pasó a varias ediciones del Romancero general). Por otra parte, Marinero soy de amor... (I, 43, 521-522) es obra de Cervantes, quien debió escribirlo en 1591, o poco antes, ya que fue en este año cuando Luis Salvador (cantor de capilla y cámara de Felipe II) musicalizó el poema; es muy posible que Cervantes sea también el autor de Yo sé, Olalla, que me adoras... (I, 9, 158-160).

Como se ve, tenemos un ligero predominio del romancero viejo sobre el nuevo (cuatro frente a tres) ${ }^{6}$. Aparentemente, este predominio disuena un poco de las modas poéticas de aquel entonces, cuando los romances nuevos gozaban de una popularidad extraordinaria... en algunos sectores (el cortesano y el urbano, sobre todo); Cervantes mismo escribió muchos de estos romances (al igual que Lope, Góngora, Liñán, Quevedo, entre otros nombres célebres). Notemos también que, con excepción del contrafactum, en el Quijote, los romances nuevos se reproducen completos y especificando quién es el supuesto autor (dentro del marco de la ficción novelesca, claro está $)^{7}$, mientras los romances viejos se citan de manera fragmentaria, apenas unos pocos versos intercalados en los parlamentos de los personajes o en el discurso del narrador:

Real, quien los usó en su traslación de los Trionfi de Petrarca. En la Segunda parte de la novela, don Quijote recurre a nuestros versos para presentarse ante don Diego de Miranda (II, 16, 151).

${ }^{6}$ En la Segunda parte, los romances viejos también dominarán sobre los nuevos (alrededor de quince sobre siete).

${ }^{7}$ En relación con Yo sé, Olalla, que me adoras..., uno de los cabreros dice así a su compañero Antonio: "Hémosle dicho [a don Quijote] tus buenas habilidades y deseamos que las muestres y nos saques verdaderos; y así, te ruego por tu vida que te sientes y cantes el romance de tus amores que te compuso el beneficiado tu tío, que en el pueblo ha parecido muy bien" (I, 5, 158). Mucho más avanzado el texto, don Luis, el falso mozo de mulas, aparece cantando Marinero soy de amor...; por las palabras de doña Clara, su enamorada, suponemos que fue el propio Luis quien compuso el romance: "todo aquello que canta lo saca de su cabeza; que he oído decir que es muy grande estudiante y poeta” (I, 43, 524). 
Para mí, señor castellano, cualquiera cosa basta, porque mis arreos son las armas, / mi descanso el pelear, etc. (I, 2, 84).

... como [don Quijote] se imaginaba que aquellas traídas y llevadas que le desarmaban eran algunas principales señoras y damas de aquel castillo, les dijo con mucho donaire:

Nunca fuera caballero / de damas tan bien servido como fuera don Quijote / cuando de su aldea vino: doncellas curaban dél, / princesas del su rocino,

o Rocinante, que éste es el nombre, señoras mías, de mi caballo (I, $2,85-86)$.

Yo hago juramento al Criador de todas las cosas y a los santos cuatro Evangelios... de hacer la vida que hizo el grande marqués de Mantua cuando juró vengar la muerte de su sobrino Valdovinos, que fue de no comer pan a manteles, / ni con su mujer folgar, y otras cosas que, aunque dellas no me acuerdo, las doy aquí por expresadas, hasta tomar entera venganza del que tal desaguisado me fizo (I, 10, 150).

Había ya vuelto en este tiempo de su parasismo don Quijote, y, con el mesmo tono de voz con que el día antes había llamado a su escudero, cuando estaba tendido en el val de las estacas, le comenzó a llamar... (I, 17, 206).

Hoy en día, tenemos que acudir a las viejas colecciones romancísticas si queremos conocer el texto completo de estos poemas ${ }^{8}$, lo que es más, dicho conocimiento es imprescindible para captar los juegos que subyacen en muchos de los romances citados en $\mathrm{El}$ Quijote $^{9}$. Con seguridad, Cervantes sabría que sus lectores inmediatos no tendrían nuestro problema, pues, para ellos el romancero viejo era cosa cotidiana, se cantaba, recitaba y oía por doquier, incluso, dentro del lenguaje corriente, a manera de frases proverbiales ${ }^{10}$. Así pues, Cervantes privilegió a los romances viejos por-

${ }^{8}$ Cf., por ejemplo, el Cancionero de romances (Amberes, s. a.), ed. facs. R. Menéndez Pidal, CSIC, Madrid, 1945, donde aparecen: Mis arreos son las armas... (f. 252), Lanzarote y el orgulloso (f. 228) y El Marqués de Mantua (ff. 29-42); como veremos más adelante, En el val de las estacas puede llevarnos al segundo tomo de la Silva de varios romances (Zaragoza, 1550), a la Rosa española de Timoneda (1573), o a un (desconocido) códice del siglo xvi, que sirvió de base a don AgusTín DuRÁN, Romancero general o Colección de romances castellanos anteriores al siglo xviii, Imp. M. Rivadeneyra, Madrid, 1849-1851, núm. 750.

${ }^{9}$ Véase David L. Garrison, "Ballad as code in Don Quijote", Neophilologus, 64 (1980), 384-389.

${ }^{10}$ R. MEnÉndez Pidal, Romancero hispánico (hispano-portugués, americano y sefardí). Teoría e historia, Espasa-Calpe, Madrid, 1968, t. 2, pp. 184-189. Además, los lec- 
que éstos eran los que podían resultar familiares a la mayoría de la gente, frente a lo que ocurría con los romances nuevos, que podían pasar de moda muy rápidamente o no llegar a conocerse en el ámbito rural, por ejemplo.

Dentro del repertorio de romances viejos citados en El Quijote hay tres romances caballerescos ( La constancia, Lanzarote y el orgulloso y El Marqués de Mantua) y sólo uno de asunto épico-nacional (En el val de las estacas...). Dado que los tres primeros aparecen, sobre todo, en boca de don Quijote, podemos suponer que, de alguna manera, el hidalgo prefería estos y no otros romances. Dicha preferencia es bastante lógica si pensamos que los romances caballerescos contribuían a reforzar la monomanía de don Quijote, convertirse en un nuevo caballero andante, y complementaban lo que él había leído en las también viejas novelas de caballerías: por ejemplo, las incomodidades de la vida andante quedaban muy bien resumidas en Mis arreos son las armas...; el romance de Lanzarote, el amante celebérrimo de la materia artúrica, traía consigo la imagen del caballero enamorado, siempre rodeado de damas y defensor de ellas ${ }^{11}$; por último, la fidelidad al linaje, así como la necesidad de vengar las ofensas hechas por los malos caballeros, concordaban maravillosamente con la historia del marqués de Mantua y su desventurado sobrino ${ }^{12}$.

tores del Siglo de Oro estaban más que acostumbrados a toparse con citas de romances dentro de obras de muy diversa índole. Parece ser que no era extraño que en las mismas novelas de caballerías se insertaran versos romancísticos, como señaló José de Perott, "Reminiscencias de romances en libros de caballerías”, RFE, 2 (1915), 289-292, a propósito de: El prisionero y Amadís de Grecia (1530, 1542); los romances de don Rodrigo y la traducción italiana del Florisando, de Páez de Ribera (Venetia, 1610); y El incendio de Roma y el Onzieme livre d'Amadis de Gaula (Lyon, 1576). Para romances derivados de este tipo de novelas, véase María Cruz García de Enterría, "Libros de caballerías y romancero", JHPh, 10 (1985), 103-115.

${ }^{11}$ D. L. GARRISOn, art. cit., p. 386.

${ }^{12} \mathrm{El}$ paralelo entre este tipo de romances y las novelas de caballerías ha sido notado por varios críticos, con propósitos muy diferentes. En relación con el problema de una posible influencia del Entremés de los romances sobre el texto cervantino, Murillo señala: "Cervantes no distingue [en los capítulos iniciales] entre libros en prosa y romances caballerescos de tradición oral porque todavía no se ha cuajado en redondo que el propósito de su libro sea extirpar los libros en prosa de caballerías", "Cervantes y El entremés de los romances", en $C H(8)$, t. 2, p. 354. Según Daniel Eisenberg ("El romance visto por Cervantes", Estudios cervantinos, Sirmio, Barcelona, 1991, pp. 58 y 72-73), Cervantes consideraba el romance similar al libro de caballerías, pues ambos géneros tenían graves defectos que el autor quería señalar a sus lectores: $a$ ) los dos estaban plagados de men- 
FORMAS DE INCORPORACIÓN DEL ROMANCERO.

Algunas FUnCiOnes DE LOS TEXTOS ROMANCísticos

En esta primera parte de la obra, el romance se incorpora de varias maneras:

a) Versos insertos como tales, con dos propósitos básicos. El más simple de ellos es el canto de un romance para reproducir un contexto de oralidad, como sucede con Yo sé, Olalla, que me adoras... y Marinero soy de amor... Las circunstancias que rodean la performan$c e$ de ambos romances podrían, muy bien, darse en la realidad de la época: en el primer caso, el cabrero Antonio "sin hacerse más de rogar, se sentó en el tronco de una desmochada encina, y, templando su rabel, de allí a poco, con muy buena gracia, comenzó a cantar", animando así la velada de sus compañeros y don Quijote (I, 11, 158); en el segundo, nos encontramos con una sentida serenata amorosa, a cargo de don Luis, el falso mozo de mulas, quien, con su sola voz, "canta que encanta", conmoviendo a todos los que lo oyen $(\mathrm{I}, 43,521)^{13}$.

Además de lo anterior, debemos considerar que el incluir estos y otros poemas sirve para romper, de vez en cuando, la monotonía del discurso prosístico, agregando variedad estilística y vitalidad al conjunto de la obra.

b) Versos incorporados a los parlamentos de los personajes o al discurso del narrador (un solo caso). Veamos un ejemplo de la primera posibilidad. Don Quijote explica a Vivaldo y compañía en qué consiste la orden de la caballería andante:

tiras, y $b$ ) algunos romances eran tan lascivos como los libros de caballerías (recordemos aquello de "no con su muger folgar"). A mí no me parece que el objetivo de Cervantes sea censurar a los romances (o la afición que la gente de la época sentía hacia ellos), por el contrario, creo que Cervantes usa los romances para jugar con ellos y, de paso, añadir cierto carácter oral a su obra.

${ }^{13}$ Parece ser que las cualidades poético-musicales de los enamorados solían causar buena impresión entre sus damas. Casi al final de la obra, el cabrero Eugenio nos narra cómo la pobre Leandra sucumbió a los encantos del pillo Vicente de la Rosa: "este bravo, este galán, este músico, este poeta fue visto y mirado muchas veces de Leandra, desde una ventana de su casa que tenía la vista a la plaza. Enamoróla el oropel de sus vistosos trajes: encantáronla sus romances, que de cada uno que componía daba veinte traslados, llegaron a sus oídos las hazañas que él de sí mismo había referido y, finalmente, que así el diablo lo debía tener ordenado, ella se vino a enamorar dél, antes que en él naciesse presunción de solicitalla" (I, 51, 593). 
Pues en tiempos deste buen rey [Arturo] fue instituida aquella famosa orden de caballería de los caballeros de la tabla Redonda, y pasaron, sin faltar un punto, los amores que allí se cuentan de don Lanzarote del Lago con la reina Ginebra, siendo medianera dellos y sabidora aquella tan honrada dueña Quintañona, de donde nació aquel tan sabido romance, y tan decantado en nuestra España, de

Nunca fuera caballero / de damas tan bien servido como fuera Lanzarote / cuando de Bretaña vino, con aquel progreso tan dulce y tan suave de sus amorosos y fuertes fechos (I, 13, 170-172).

Aquí don Quijote subraya los nexos que existen entre las novelas de caballerías y el romancero caballeresco, entre el pasado lejano y fabuloso a que remiten estas historias y el presente español donde se sigue cantando el romance de Lanzarote. El argumento de don Quijote podría ser el siguiente: este romance narra una historia de los tiempos en que se fundó la caballería andante, si todavía se canta, ¿qué de extraño tiene que ahora yo intente revivir tan gloriosa orden?, si Lanzarote fue tan buen caballero y amante, ¿por qué he de ser menos yo? (Volveremos sobre el particular.) Otros casos de versos incorporados a los parlamentos de los personajes son: Mis arreos son las armas... (I, 2, 84), Lanzarote (I, 2, 85), El Marqués de Mantua (I, 5, 103; 10, 150; 19, 228).

En ocasiones, los versos están usados como elementos fraseológicos del idioma, siguiendo uno de los usos habituales en el lenguaje de la época, tal vez éste sea el caso de "Mis arreos son las armas...", cuando aparece en boca de don Quijote; más claro aún, es el ejemplo de "en el val de las estacas", usado por el narrador al principio del capítulo 17:

Había ya vuelto en este tiempo de su parasismo don Quijote, y, con el mesmo tono de voz con que el día antes había llamado a su escudero, cuando estaba tendido en el val de las estacas, le comenzó a llamar... (I, 7, 206).

Pero, como en tiempos de Cervantes y como sigue ocurriendo en nuestros días, el manejo de una frase proverbial puede tener segundas intenciones, y éstas son, precisamente, las del narrador (quien, a pesar de usar muy poco el romancero, sabe sacar provecho del género). El verso en cuestión inicia dos romances cidianos, de asunto muy similar; en el primero, el Campeador va a recoger las parias que un rey moro debe al rey castellano: 
Por el val de las estacas / pasó el Cid a mediodía, en su caballo Babieca, / ¡oh, qué bien que parecía! El rey moro que lo supo / a recibirlo salía

$\cdots$

-No te las daré yo, el buen Cid, / Cid, yo no te las daría, si mi padre las pagó, / hizo lo que no debía.

-En cuanto a eso, rey moro, / creo que nada te debía, que si buena lanza tienes, / por buena tengo la mía, mas da sus parias al rey, / a ese buen rey de Castilla.

-Por ser vos su mensajero, / de buen grado las daría ${ }^{14}$.

El segundo de estos romances narra el enfrentamiento del Cid y el moro Abdalla:

Por el val de las estacas / el buen Cid pasado había, a la mano izquierda deja / la villa de Constantina.

En su caballo Babieca / muy gruesa lanza traía, va buscando al moro Abdalla, / que enojado le tenía,

-Muchos tiempos ha, el buen Cid, / que esperaba yo este día, porque no hay hombre nacido / de quien yo me escondería, porque desde mi niñez / siempre huí de cobardía.

-Alabarte, moro Abdalla, / poco te aprovecharía, mas si eres tal cual tú hablas, / en esfuerzo y valentía, a tiempo eres venido, / que menester te sería.

Estas palabras diciendo, / contra el moro arremetía, encontróle con la lanza / y en el suelo lo derriba, cortárale la cabeza, / sin le hacer cortesía (núm. 752).

Retengamos los elementos presentes en ambos textos: la gloriosa figura del Cid montado en Babieca; el Campeador se enfrenta a un moro distinguido (rey, guerrero), a quien -por supuesto- vence, indirecta o directamente gracias a su lanza. Cuando el narrador del Ingenioso hidalgo... utiliza la frase "en el val de las estacas", seguramente, sabe que los lectores recordarán alguno de los romances citados y, lo que es más, sabe que dichos lectores contrastarán la materia cidiana con las infortunadas aventuras que don Quijote acaba de pasar, en los dos capítulos anteriores: el episodio de los yangüeses y la primera noche en la venta de Juan Palomeque.

14 Agustín Durán, op. cit., núm. 750. 
En el capítulo 15, los intentos amorosos de Rocinante con las "señoras facas" provocan que los arrieros yangüeses -estacas y palos en mano- propinen soberbia paliza al caballo, al caballero y su escudero, quedando, muy democráticamente, todos juntos y en el suelo:

... al segundo toque dieron con Sancho en el suelo, y lo mesmo le avino a don Quijote, sin que le valiese su destreza y buen ánimo; y quiso su ventura que viniese a caer a los pies de Rocinante, que aún no se había levantado; donde se echa de ver la furia con que machacan estacas puestas en manos rústicas y enojadas (I, 15, 191-192) ${ }^{15}$.

El contraste entre los dos "val de las estacas" no puede menos que mover a risa, sobre todo, considerando que Rocinante, el caballo que don Quijote cree superior a Bucéfalo y Babieca (I, 1, 76), fue el causante de la desgracia, todo lo contrario del veloz y austero Babieca, que, cuando se humaniza, lo hace sólo para ayudar a su amo ${ }^{16}$.

Los golpes continúan. Rocinante debió contagiar sus deseos amorosos a don Quijote, ya que, en el capítulo 16, este último ataca a Maritornes, creyendo que la moza es una hermosísima doncella que "a furto de sus padres, vendría a yacer con él una buena pieza" (I, 16, 202). Las intenciones de la asturiana eran yacer con... el arriero, que dormía al otro lado de la habitación y que, sintiéndose traicionado, arremete contra nuestro hidalgo. Con la intervención de Maritornes, Sancho y el ventero, la batalla se arma, el capítulo termina cuando -por segunda vez- don Quijote acaba molido y en el piso. Es probable que las resonancias de "en el val de las estacas" lleguen hasta este episodio, al menos en lo que se refiere a la presencia del arriero, que, por su profesión y "parentesco" con Cide Hamete ${ }^{17}$, podría servir de contrapunto paródico a los adversarios del Cid.

15 Más adelante, Sancho recordará el "molimiento de las estacas" (I, 17, 208), y, el narrador, hablando del mismo Sancho, se referirá a las "bendiciones de las estacas" (I, 23, 284).

${ }^{16}$ En el romance del Rey moro que perdió Valencia, el Cid va persiguiendo al moro, hasta casi alcanzarlo, y, de repente, resulta que ambas cabalgaduras están emparentadas: "Do la yegua pone el pie, / Babieca pone la pata. // Allí hablara el caballo, / bien oiréis lo que hablaba: / / ¡Reventar debía la madre / que a su hijo no esperaba! - / / Siete veces la rodea / alrededor de una jarra; / / la yegua, que era ligera, / muy adelante pasaba", dejando atrás a su hijo y al jinete de éste, Cancionero de romances (Amberes, s. a.), f. 179.

17 “...era uno de los ricos arrieros de Arévalo, según lo dice el autor desta historia [aquí: Cide Hamete Benengeli] que deste arriero hace particular men- 
c) Versos glosados dentro del discurso de los personajes o, muy eventualmente, del narrador. Hemos citado ya el caso de Mis arreos son las armas..., lo que no hemos dicho es qué le contesta el primer ventero a don Quijote, he aquí la respuesta:

-Si vuestra merced, señor caballero, busca posada, amén del lecho (por que en esta venta no hay ninguno), todo lo demás se hallará en ella con mucha abundancia.

-Para mí, señor castellano, cualquiera cosa basta, porque mis arreos son las armas, / mi descanso el pelear, etc.

-Según eso, las camas de vuestra merced serán duras peñas, y su dormir, siempre velar; y siendo así, bien se puede apear, con seguridad de hallar en esta choza ocasión y ocasiones para no dormir en todo un año, cuanto más en una noche (I, 2, 84-85).

Esta es la primera vez que el romance aparece en la obra ${ }^{18}$, y ya desde aquí se nos dan algunas de las pautas que guiarán la inserción del primero en la segunda.

Por principio de cuentas, es don Quijote quien introduce el género, lo cual es significativo porque la mayoría de las alusiones las hace o las provoca él, al menos, en lo que se refiere al texto de $1605^{19}$. El diálogo con el ventero ilustra las dos posibilidades que acabamos de mencionar. Por un lado, don Quijote apenas se está auto-configurando como caballero andante ${ }^{20}$, quizá busca hacer méritos para que el ventero (que él cree el señor de castillo) lo

ción, porque le conocía muy bien, y aun quieren decir que era algo pariente suyo" (I, 16, 201).

${ }^{18}$ La frase, "En un lugar de la Mancha", forma parte del romance con que se abre cierta ensalada anónima: "Un lencero portugués, / recién venido a Castillas, / más valiente que Roldán / y más galán que Macías, / en un lugar de la Mancha, / que no le saldrá en su vida, / se enamoró muy despacio, / de una bella casadilla..."; la ensalada se incluyó en las Flores del Parnaso. Octava parte, recopilada por Luys de Medina (Toledo, 1596, f. 112), y pasó al Romancero general de 1600 (en la ed. de A. González Palencia, CSIC, Madrid, 1947, pp. 532-533). No se sabe cuál fue la fuente del verso de la ensaladilla, me inclino a creer que se trata de una fórmula de inicio de cuento folclórico, más que de un verso de romance viejo.

${ }^{19}$ Las excepciones son, por supuesto, los romances de Antonio y don Luis. En el caso de En el val de las estacas..., ¿no estaríamos también frente a una "provocación" indirecta de don Quijote? El "monopolio" romancístico de nuestro hidalgo desaparece en la Segunda parte de la novela, donde es Sancho quien lleva la voz cantante, en aquello de citar romances.

20 Tiene armas, caballo, dama y nombres (Rocinante, Dulcinea del Toboso, don 
arme caballero, quizá por eso se vale de "Mis arreos son las armas / mi descanso el pelear" para mostrarle a su interlocutor que él, como todo buen caballero andante, siempre piensa más en las hazañas guerreras que en las comodidades materiales; por el otro, el ventero ha visto y oído lo suficiente para saber que el recién llegado está loco, pero, como todo hombre de buen humor, decide seguirle la corriente completando (muy a su manera) la cita del romance.

En el capítulo 5 aparecen las primeras alusiones al Marqués de Mantua, que se proyectarán hasta el capítulo 31 y, después, al texto de 1615 . El poema se recuerda a partir de dos momentos básicos: por un lado, el encuentro de Valdovinos moribundo y su tío, por el otro, el juramento que hace el marqués para vengar la muerte de su sobrino. Como veremos, el primer momento se da en el citado capítulo 5, sobre todo, a través de don Quijote, pero el narrador pone su granito de arena y glosa algunos versos del romance para describir las acciones de Pedro Alonso (I, 5, 104). El segundo momento aparece a partir del capítulo 10, en circunstancias muy similares a las del diálogo de la primera venta. Como el ventero, Sancho también retomará versos de un romance que ha oído a don Quijote ("no comer pan a manteles, / ni con su mujer folgar", a propósito del Marqués de Mantua, I, 10, 150) ${ }^{21}$; en una ocasión, Sancho cita casi los mismos versos que su amo ("no comer pan a manteles ni con la reina folgar", I, 19, 228) ${ }^{22}$, pero, por lo general, prefiere glosar otros ("el dormir vestido, y el no

Quijote de la Mancha), en este momento, su preocupación básica es conseguir quien lo arme caballero.

${ }^{21}$ En este viejo romance juglaresco, el marqués jura vengar la muerte de su sobrino en los siguientes términos: "Juro por Dios poderoso / y por Santa María, su madre, // y al santo sacramento / que aquí suelen celebrare // de nunca peynar mis canas, / ni las mis barvas cortare, // de no vestir otras ropas / ni renovar mi calçare, // de no entrar en poblado, / ni las armas me quitare // si no fuere una hora / para mi cuerpo alimpiare, // de no comer a manteles, / ni a la mesa me asentare, // fasta matar a Carloto / por justicia o peleare, // o morir en la demanda / manteniendo la verdade...", Cancionero de romances (Amberes, s. a.), f. 41. Juramentos semejantes se encuentran en otros romances carolingios (Conde Dirlos, Desafío de Montesinos a Oliveros); para Menéndez Pidal este tipo de acumulación de votos viene de la épica francesa (Romancero hispánico, t. 1, pp. 267-268).

${ }^{22}$ En ninguna de las versiones conocidas del romance hay algo parecido a "ni con muger folgar" o "ni con la reina folgar", en cambio, este último verso figura en Las quejas de Jimena: "Rey que non faze justicia, / non deviera de reinare, // ni cavalgar en cavallo, / ni con la reina holgare, // ni comer pan a manteles, / ni menos armas se armare...", JuAn DE Escobar, Historia y romancero del Cid 
dormir en poblado", I, 10, 151; "sin comer pan a manteles ni sin peinarse la barba", I, 31, 383). Esta iniciativa implica que el escudero también tenía su propio bagaje romancístico ${ }^{23}$.

d) Desarrollo de episodios con base en textos o recuerdos romancísticos. En el texto de 1605 este recurso se da durante la primera salida de don Quijote, cuando éste se cree Valdovinos (cap. 5); en la segunda, el romancero inspirará dos episodios: el de la cueva de Montesinos (romances de Durandarte y Belerma, cap. 23) y el retablo de maese Pedro (romances de Gaiferos y Melisendra, cap. 26).

\section{La PRIMera SAlida De don Quijote: "El Marqués de Mantua"}

Hemos dicho que el romancero aparece poco en esta Primera parte de la obra, sin embargo, es curioso que sea en los capítulos iniciales donde se desencadenan las citas romancísticas, como si el romance cobrara una fuerza que después no germinó o no se quiso mantener.

La primera salida de don Quijote abarca los capítulos 2 a 5 . Como vimos, en el segundo capítulo don Quijote introduce a nuestro género, mediante su diálogo con el primer ventero; muy poco después, las mozas del partido ayudan al recién llegado a desarmarse (hasta donde es posible), la reacción de éste no se hace esperar y les recita parte de Lanzarote y el orgulloso, permitiéndose una que otra manipulación del texto viejo:

Nunca fuera caballero / de damas tan bien servido como fuera don Quijote / cuando de su aldea vino: doncellas curaban dél, / princesas del su rocino,

(Lisboa, 1605), ed. A. Rodríguez-Moñino, Castalia, Madrid, 1973, p. 131; mismo pasaje en la Rosa española de Timoneda, y en el Cancionero de romances (Amberes, 1550), ed. A. Rodríguez-Moñino, Castalia, Madrid, 1967, p. 225. A menos que Cervantes recordara una versión desconocida del Marqués de Mantua, es posible que estuviera fusionando, consciente o no, hemistiquios que pertenecían a dos romances diferentes; según Rodríguez Marín, Cervantes se transcordó y atribuyó al Marqués lo que había leído (¿por qué no oído?) en Las quejas (ed. cit., t. 1, p. 302, nota).

${ }^{23} \mathrm{Al}$ respecto, EISENBerg ha señalado que, fuera de don Quijote y el narrador, en ésta y otras obras de Cervantes, "los romances se asocian con la clase baja o no hidalga"; cita como ejemplos a Sancho, la doña Rodríguez, el labrador del Toboso, gitanos y Juliana la Cariharta de Rinconete y Cortadillo (art. cit., p. 79, nota). Tal vez, Cervantes quería subrayar el carácter popular de los romances viejos. 
o Rocinante, que éste es el nombre, señoras mías, de mi caballo, y don Quijote de la Mancha el mío; que, puesto que no quisiera descubrirme fasta que las fazañas fechas en vuestro servicio y pro me descubrieran, la fuerza de acomodar el propósito presente este romance viejo de Lanzarote ha sido la causa que sepáis mi nombre antes de toda sazón (I, 2, 85-86) ${ }^{24}$.

El hecho de que nuestro hidalgo se valga de este romance para declarar, por primera vez, su nombre no debe ser ocioso, pues, seguramente, el nombre del bretón fue uno de los orígenes de don-Qui-jo-te ${ }^{25}$. El todavía novel caballero sabe que tiene mucho en común con Lanzarote, y, por eso, continúa acomodando la realidad a su manera: si la venta es castillo, el porquero, heraldo, y el ventero, castellano, las mozas del partido no serán tales sino señoras, ¡doncellas! o princesas (pues todo buen caballero suele estar rodeado de ellas) ${ }^{26}$. Por supuesto, el desatino de don Quijote es tremendo, pero, algo había ya en el romance viejo que se prestaba a la parodia: por ejemplo, el contraste entre la alta calidad de las damas, y del propio Lanzarote, y el hecho de que la cabalgadura de este último sea un simple rocín ${ }^{27}$.

${ }^{24}$ El romance decía así: "Nunca fuera cavallero / de damas tan bien servido // como fuera Lançarote / cuando de Bretaña vino: // que dueñas curavan dél, / donzellas del su rocino, // essa dueña Quintañona, / se lo acostava consigo...", Cancionero de romances (Amberes, s. a.), f. 228.

25 Desgraciadamente, no he podido consultar el trabajo de L. A. Murillo, "Lanzarote and Don Quijote", que, sin duda, sería muy esclarecedor para éste y otros pasajes relacionados con la balada. Por ello recurro a las notas que este mismo investigador incluye en la edición que utilizo: "en la mente de Cervantes don-Quijo-te y Lan-za-ro-te hacían una especie de paronomasia” (I, 1, 76-77, nota). Otras fuentes debieron ser: la raíz del apellido del hidalgo (Quijada o Quixano) y el nombre de una pieza de la armadura defensiva que cubría el muslo (quijote); además, el sufijo -ote tiene un matiz ridículo en castellano (monigote, librote, mitote), también conviene recordar a un personaje del Primaléon (1535), el "fidalgo Camilote", escudero ridículo y feo que ante el rey pide que se le arme caballero.

${ }^{26} \mathrm{El}$ romance reaparece en la Segunda parte. Cuando don Quijote y Sancho llegan al palacio de los duques; el ingenuo escudero le pide a la dueña Rodríguez que se encargue de su rucio, ante el enojo de ésta, Sancho se justifica diciendo lo que ha oído decir a su amo sobre Lanzarote, "Cuando de Bretaña vino...", etc., etc. (II, 31, 275). Evidentemente, este episodio es un eco voluntario del que estamos tratando.

27 Como dice Murillo, el antiguo romance expresaba "una visión ya deformada, humorística y popular, del caballero medieval" (I, 2, 85-86, nota). Que el rocín era una cabalgadura indigna de un caballero nos lo dice el romance del conde Almerique de Narbona: "cativado han al conde, / al conde Benalmenique: // descienden lo de una torre, / cavalgan lo en un rocín, // la cola le dan 
Ya armado caballero, don Quijote sale de la venta. En el capítulo 4 lo vemos muy orondo, pues cree haber realizado su primera hazaña: liberar a Andrés de los azotes que le daba su amo, Juan Haldudo. Todo parece ir muy bien para el incipiente caballero ("que hoy ha desfecho el mayor tuerto y agravio que formó la sinrazón y cometió la crueldad”, I, 4, 99), pero, al toparse con los mercaderes toledanos (en su opinión, caballeros andantes), la fortuna se le revela adversa. Don Quijote, que ha pretendido que los toledanos declaren a Dulcinea la doncella más hermosa del mundo, no soporta las burlas que uno de ellos hace sobre su dama, y, lanza en mano, arremete contra el mercader, con tal mala suerte que Rocinante cae en mitad del camino, dejando a su amo tirado en el suelo. Uno de los mozos de mulas de los comerciantes da al hidalgo su primera paliza. ¿El instrumento? Los restos de la lanza del propio caballero ${ }^{28}$. El capítulo 4 termina con don Quijote tirado en el suelo y sin poderse mover, a causa de los golpes recibidos, el capítulo siguiente ("Donde se prosigue la narración de la desgracia de nuestro caballero") comienza así:

Viendo, pues, que, en efecto, no podría menearse, acordó de acogerse a su ordinario remedio, que era pensar en algún paso de sus libros, y trújole su locura a la memoria aquel de Valdovinos y del marqués de Mantua, cuando Carloto lo dejó herido en la montiña... Esta [historia] le pareció a él que le venía de molde para el paso en que se hallaba; y así, con muestras de grande sentimiento, se comenzó a volcar por la tierra, y a decir con debilitado aliento lo mesmo que dicen decía el herido caballero del bosque (I, 5, 102-103).

¡Don Quijote se cree Valdovinos moribundo! Hay algo extraño en todo esto. Se nos ha dicho -y se nos dice en este pasaje- que la obsesión del hidalgo es imitar las hazañas de los héroes de las novelas de caballerías, y, de repente, resulta que don Quijote no sólo se acuerda de un romance sino que asume la personalidad de uno de los personajes del poema. Afloran la citas romancísticas. En primer lugar tenemos:

por riendas / por más deshonrado yr", Cancionero de romances (Amberes, 1550), p. 318. Rocin: "el caballo de mala traza y flaco", "se llama comúnmente el caballo de trabajo, a distinción del que llaman de regalo" (Dicc. Aut., s.v. "rocín”).

28 "Y llegándose a él, tomó la lanza y, después de haberla hecha pedazos, con uno dellos comenzó a dar a nuestro don Quijote tantos palos, que, a despecho y pesar de sus armas, le molió como cibera... y acudiendo por los demás trozos de la lanza, los acabó de deshacer sobre el miserable caído” (I, 4, 101). 
¿Dónde estás, señora mía,

que no te duele mi mal?

O no lo sabes, señora,

o eres falsa y desleal (I, 5,103$)$.

Se supone que estos versos son "lo mesmo que dicen decía el herido caballero del bosque”, pero no es así, porque el romance viejo es ligeramente diferente: “¿Dónde estás, señora mía, / que no te pena mi male? // De mis pequeñas heridas / compassión solías tomare, // agora de las mortales / no tienes ningún pesare..."29. Lo que sucede es que don Quijote, que tiene varias cosas revueltas en la cabeza, en este momento y sólo aquí, está recordando versos de un romance nuevo, contrahecho sobre el antiguo del Marqués de Mantua.

Don Quijote vuelve al romance viejo, sin dejar de cometer incongruencias, como cuando dice: "¡Oh, noble marqués de Mantua, / mi tío y señor carnal!” (I, 5, 103), por “¡Oh, noble marqués de Mantua, / mi señor tío carnale!" (f. 33). Por si fuera poco, todas las circunstancias inmediatas contribuirán a que don Quijote siga con su delirio. Como hace el marqués en el romance, el labrador Pedro Alonso se acerca al caído para preguntarle "quién era y qué mal sentía, que tan tristemente se quejaba", ante este estado de cosas, nuestro hidalgo no puede menos que creer que su interlocutor es el propio marqués, "y así, no le respondió otra cosa si no fue proseguir en su romance" (I, 5, 104). Hasta ahora, el labrador no ha reconocido a don Quijote, su vecino; el narrador, que ha estado detrás de todo esto, aprovecha otros versos del romance para explicar el reconocimiento:

El labrador estaba admirado oyendo aquellos disparates; y quitándole la visera, que ya estaba hecha pedazos, de los palos, le limpió el rostro, que le tenía cubierto de polvo, y apenas le hubo limpiado, cuando le conoció $(i d$.$) .$

Pedro Alonso actúa igual que el marqués: “desque le quito el almete / començóle de mirare: // ... // con un paño que traya / la cara le fue a limpiare, // desque la ovo limpiado / luego conocido lo hae..." (f. 36). Don Quijote sigue inmerso en su delirio romancístico, Pedro Alonso lo levanta y decide regresarlo a casa; el hidalgo suspira y el labrador le vuelve a preguntar qué le pasa, ahora, don Quijote ya no es Valdovinos sino Abindarráez, conducido por Rodrigo de Narváez a la alcaldía. El romance fue sustituido por la novela morisca, y, con estas pláticas, don Quijote llega a casa.

29 Cancionero de romances (Amberes, s. a.), f. 32. 
Ante este estado de cosas, uno no puede menos que preguntarse por qué don Quijote empieza sus andanzas adoptando la personalidad de héroes que no pertenecen a las novelas de caballerías, causa señalada de su locura, desde el primer capítulo. La pregunta conlleva varios problemas. Quizá el más importante tiene que ver con las similitudes que hay entre este episodio y un anónimo Entremés de los romances, cuyo protagonista enloquece de tanto "leer el romancero" e imita ridículamente las hazañas de sus héroes romancísticos ${ }^{30}$; la pieza teatral apareció en la tercera parte de las Comedias de Lope de Vega (¿Valencia, 1611?, ¿Barcelona, 1612?), pero contiene ciertas alusiones (Francis Drake, la reina Isabel, el conflicto con Inglaterra), que de ser contemporáneas, pueden llevarnos a 1588-159731. Las semejanzas entre las dos obras son las siguientes: ambos protagonistas son apaleados con su propia lanza, caen y echan la culpa a su cabalgadura; ambos creen ser Valdovinos y recuerdan trozos del Marqués de Mantua (Bartolo sigue siempre la versión antigua), y, cuando son auxiliados, ambos creen que quien acude es el marqués, en persona. Después de esto, Bartolo adopta la personalidad de uno de los Abencerrajes.

Los paralelos entre el episodio cervantino y el anónimo entremés han intrigado a muchos críticos, dando lugar a todo tipo de opiniones: Cervantes es el autor de ambas obras (Alonso de Castro), el Entremés es anterior y sirvió de inspiración a Cervantes (Menéndez Pidal), el Entremés imita al texto cervantino (Emilio Cotarelo y Mori, Rodolfo Schevill), el Entremés es contemporáneo a la escritura del Quijote, pero no lo imita directamente (Murillo). Ante semejante estado de cosas, no podemos terciar en la batalla. De ahí que, al margen de este problema de influencias, apuntemos que la primera salida de don Quijote ha sido muy breve, como si el héroe todavía no estuviera listo para comenzar su "verdadero" recorrido (ya con escudero y comparsa, y con el claro objetivo de imitar sólo a los caballeros de sus amadas novelas). ¿Estaría Cervantes tanteando el camino para, después, lanzar definitivamente a su héroe?, ¿lo haría conscientemente?, ¿buscaba sorprendernos con una incongruencia deliberada? Todo puede ser.

Magdalena Altamirano

${ }^{30}$ La versión moderna del texto en Emilio Cotarelo y Mori, Colección de entremeses, loas, bailes, jácaras y mojigangas, BAE, 17, Madrid, 1911, pp. 157-176.

${ }^{31}$ Para los problemas de datación, véanse, sobre todo, las opiniones de JuAN Millé y Giménez, Sobre la génesis del “Quijote”, Araluce, Barcelona, 1930, esp. pp. 97 ss., R. Menéndez Pidal, art. cit. y Murillo, art. cit. 